\title{
Front Matter: Volume 10815
}

, "Front Matter: Volume 10815," Proc. SPIE 10815, Optical Design and Testing VIII, 1081501 (7 November 2018); doi: 10.1117/12.2521302

SPIE. Event: SPIE/COS Photonics Asia, 2018, Beijing, China 


\title{
PROCEEDINGS OF SPIE
}

\section{Optical Design and Testing VIII}

\author{
Yongtian Wang \\ Tina E. Kidger \\ Kimio Tatsuno \\ Editors
}

\section{1-13 October 2018 \\ Beijing, China}

Sponsored by

SPIE

COS_Chinese Optical Society

Cooperating Organizations

Tsinghua University (China) • Peking University (China) • University of Science and Technology of China (China) • Zhejiang University (China) - Tianjin University (China) - Beijing Institute of Technology (China) • Beijing University of Posts and Telecommunications (China) • Nankai University (China) - Changchun University of Science and Technology (China) • University of Shanghai for Science and Technology (China) • Capital Normal University (China) • Huazhong University of Science and Technology (China) - Beijing Jiaotong University (China) - Shanghai Institute of Optics and Fine Mechanics (China) - Changchun Institute of Optics and Fine Mechanics (China) - Institute of Semiconductors (China) - Institute of Optics and Electronics (China) - Institute of Physics (China) • Shanghai Institute of Technical Physics (China) • China Instrument and Control Society (China) - Optoelectronics Technology Committee, COS (China) • Optical Society of Japan (Japan) • Optical Society of Korea (Korea, Republic of) • The Australian Optical Society (Australia) • Optics and Photonics Society of Singapore (Singapore) • European Optical Society

Supporting Organizations

CAST_China Association for Science and Technology (China)

NSFC-National Nature Science Foundation (China)

Published by

SPIE

\section{Volume 10815}


The papers in this volume were part of the technical conference cited on the cover and title page. Papers were selected and subject to review by the editors and conference program committee. Some conference presentations may not be available for publication. Additional papers and presentation recordings may be available online in the SPIE Digital Library at SPIEDigitallibrary.org.

The papers reflect the work and thoughts of the authors and are published herein as submitted. The publisher is not responsible for the validity of the information or for any outcomes resulting from reliance thereon.

Please use the following format to cite material from these proceedings:

Author(s), "Title of Paper," in Optical Design and Testing VIII, edited by Yongtian Wang, Tina E. Kidger, Kimio Tatsuno, Proceedings of SPIE Vol. 10815 (SPIE, Bellingham, WA, 2018) Seven-digit Article CID Number.

ISSN: 0277-786X

ISSN: 1996-756X (electronic)

ISBN: 9781510622289

ISBN: 9781510622296 (electronic)

Published by

SPIE

P.O. Box 10, Bellingham, Washington 98227-0010 USA

Telephone +1 3606763290 (Pacific Time) · Fax +1 3606471445

SPIE.org

Copyright @ 2018 , Society of Photo-Optical Instrumentation Engineers.

Copying of material in this book for internal or personal use, or for the internal or personal use of specific clients, beyond the fair use provisions granted by the U.S. Copyright Law is authorized by SPIE subject to payment of copying fees. The Transactional Reporting Service base fee for this volume is $\$ 18.00$ per article (or portion thereof), which should be paid directly to the Copyright Clearance Center (CCC), 222 Rosewood Drive, Danvers, MA 01923. Payment may also be made electronically through CCC Online at copyright.com. Other copying for republication, resale, advertising or promotion, or any form of systematic or multiple reproduction of any material in this book is prohibited except with permission in writing from the publisher. The CCC fee code is 0277$786 \mathrm{X} / 18 / \$ 18.00$.

Printed in the United States of America.

Publication of record for individual papers is online in the SPIE Digital Library.

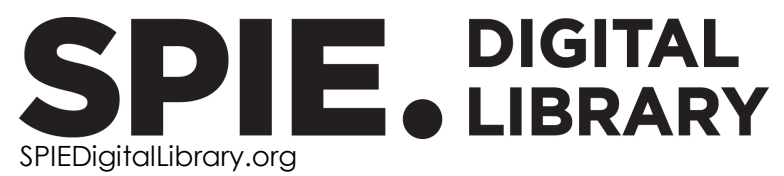

Paper Numbering: Proceedings of SPIE follow an e-First publication model. A unique citation identifier (CID) number is assigned to each article at the time of publication. Utilization of CIDs allows articles to be fully citable as soon as they are published online, and connects the same identifier to all online and print versions of the publication. SPIE uses a seven-digit CID article numbering system structured as follows:

- The first five digits correspond to the SPIE volume number.

- The last two digits indicate publication order within the volume using a Base 36 numbering system employing both numerals and letters. These two-number sets start with $00,01,02,03,04$, 05, 06, 07, 08, 09, 0A, OB ... 0Z, followed by 10-1Z, 20-2Z, etc. The CID Number appears on each page of the manuscript. 


\title{
Contents
}

\author{
vii Authors \\ ix Symposium Committees \\ xiii Conference Committee
}

TRANSMISSION AND INTERFEROMETRIC STUDIES

1081503 CGH and stitching technique: powerful combination enabling full-surface figure measurements of certain classes of aspheres (Invited Paper) [10815-3]

1081504 Optical design and accuracy analysis of interferometric star tracker [10815-4]

1081505 Calibration of probe misalignment in point-diffraction interferometer [10815-5]

1081506 Effect of defects on filtering performance of one-dimensional photonic crystals [10815-6]

1081507 Surface plasmon-assisted transmission in dual metallic film [10815-7]

LENS DESIGN AND FABRICATION METHODS

$108150 \mathrm{~A} \quad$ Design of multizone soft contact lens to slow myopia progression [10815-10]

10815 OB Wavefront predictions for the automated assembly of optical systems [10815-11]

\section{ASPECTS OF TELESCOPIC OPTICS}

10815 OD Large dynamic range wavefront sensing using Shack-Hartmann wavefront sensor based on pattern correlations (Invited Paper) [10815-13]

10815 OE Optical design for three sub-mirror sparse aperture with freeform surface [10815-14]

10815 OF Stray light suppression of a compact off-axis telescope for a satellite-borne instrument for atmospheric research [10815-15]

$108150 \mathrm{O}$ Phasing error detection for segmented telescopes [10815-16] 
$10815 \mathrm{OH}$ Color temperature changeable adaptive driving beam for enhanced human perception (Invited Paper) [10815-17]

1081501 Characterization of angle-resolved measurement of diffuse reflected light (Invited Paper) [10815-18]

10815 0J Improvement of color gamut in laser quantum dots backlight display (Invited Paper) [10815-19]

10815 OK Freeform lens design for laser diode beam shaping (Invited Paper) [10815-20]

$10815 \mathrm{OL}$ Acousto-optical tunable filter for a swept light source with variable transmission function [10815-21]

$108150 \mathrm{M}$ Annular oblique epi-illumination design for ultra-large-scale and high-resolution fluorescence microscopy [10815-22]

\section{STRAY LIGHT ANALYSIS AND TEST TECHNIQUES}

10815 OP Diffraction method for inspecting the defects of lenses with various curvature [10815-25]

$108150 Q \quad$ Systematic parameter calibration in the wavefront testing with reverse Hartmann test [10815-26]

10815 OR Monte Carlo calculation on stray radiation scattered by the baffle with a heterotypic surface for uncooled infrared system [10815-28]

10815 OS RGB camera-based functional imaging of in vivo biological tissues (Invited Paper) [10815-66]

\section{IMAGING STUDIES AND IMPLEMENTATION}

10815 OT Multi-dimensional digital holographic microscopy (Invited Paper) [10815-2]

10815 OU Analysis of the visual perception conflicts in designing mixed reality systems [10815-29]

10815 OW Design of UV LED illumination system for direct imaging lithography [10815-31] 
$108150 X \quad$ Scanning distortion analysis of infrared thermal imagers systems [10815-32]

$108150 Y$ Development and practical test of portable laser communication optical system [10815-33]

1081511 A GEO satellite working state detection method based on photometric characteristics [10815-37]

1081512 The construction of frontal components of objectives for microscope: optical design [10815-38]

1081513 The possibility of expanding the spectral range for lens microscope objectives: examples of optical design [10815-39]

1081515 The field mosaic method of wide-angle telescope array for typical track general survey [10815-41]

1081516 Modeling and analysis for the mirror tilt angle error of the image mapper [10815-42]

1081517 Mode interactions in a three-layered slab waveguide with periodic structures [10815-43]

1081518 Multi-type hyperspectral imaging integrated system [10815-44]

$108151 \mathrm{~A}$ Simulation of eye's wavefront aberration measurement based on annular radial shearing interferometry [10815-46]

$108151 \mathrm{~B} \quad$ Optimizing double freeform surfaces for reducing deviations in ray-mapping method [10815-47]

$108151 \mathrm{E}$ Tolerances and alignment method for high-aperture hybrid diffractive-reflective objective [10815-51]

$10815 \mathrm{lF} \quad$ Method of object MRTD-testing for thermal infrared imager [10815-52]

$108151 \mathrm{H}$ Thermal stress of MOEMS accelerometers based on grating interferometric cavity [10815-54]

$108151 \mathrm{M}$ Comparative analysis of mid-spatial frequency errors measurement using multiple phase retrieval algorithms [10815-59]

1081510 Continuous zoom laser beam shaper with microlens arrays [10815-61]

$108151 \mathrm{P}$ Peculiarities of optical element manufacturing in the Chinese optical industry [10815-62]

$108151 Q \quad$ Optimal parameter solution for optical design of testing large-aperture off-axis aspheric mirror with computer-generated holograms [10815-63]

10815 IR Stretchable phase-mode Fresnel zone plates for focus tuning [10815-64] 
10815 is Freeform surface optical design of Zernike polynomials based on nodal aberration theory [10815-65] 


\section{Authors}

Numbers in the index correspond to the last two digits of the seven-digit citation identifier (CID) article numbering system used in Proceedings of SPIE. The first five digits reflect the volume number. Base 36 numbering is employed for the last two digits and indicates the order of articles within the volume. Numbers start with 00, 01, 02, 03, 04, 05, 06, 07, 08, 09, OA, OB...0Z, followed by 10-1Z, 20-2Z, etc.

\author{
Ai, Zhenyi, 16 \\ Aizu, Yoshihisa, OS \\ An, Yan, OY \\ Awatsuji, Yasuhiro, OT \\ Bai, Jian, 04, 1H, 1M \\ Batshev, Vladislav I., OL \\ Bian, Yayan, OA \\ Bibi, Aysha, 17 \\ Bogdanov, Nikolay, OU \\ Cai, Daling, OE \\ Cao, Ling, OR \\ Cen, Zhaofeng, OP \\ Chang, Shuai, OY \\ Chen, Baohua, OE \\ Chen, Cheng, IR \\ Chen, Jian, 07 \\ Chen, Jianfa, is \\ Chen, Jianjun, OW \\ Chen, Jinjin, OR \\ Chen, Liang, OJ \\ Chen, Linsen, IR \\ Chen, Peiwen, $1 \mathrm{H}$ \\ Chen, Xinhua, 10 \\ Chen, Xiyao, 06 \\ Chen, Yan-ping, $1 \mathrm{~A}$ \\ Chen, Yu, OJ \\ Chen, Zhangmin, OP \\ Cheng, Dewen, OK, 1B \\ Choi, Eun Jung, $\mathrm{OH}$ \\ Christensen, Ole Martin, OF \\ Dai, Qian, 07 \\ Ding, Xiaoming, 16 \\ Dong, Keyan, OY \\ Du, Juan, 04, $1 \mathrm{M}$ \\ Du, Xiaoyu, OX \\ Emrich, Anders, OF \\ Fan, Junliu, OE \\ Fan, Ya-Xian, 17 \\ Fang, Weidong, $1 \mathrm{H}$ \\ Feng, Zexin, OK, 1B \\ Frolov, Alexey D., 12 \\ Frolov, Dmitry N., 12, 13 \\ Frolov, Vladimir N., 13 \\ Gorevoy, Alexey V., OL \\ Hammar, Arvid, OF \\ Han, Dandan, $1 \mathrm{H}$ \\ He, Qing, 18 \\ $\mathrm{Hu}$, Jing, $O M$ \\ $\mathrm{Hu}$, Weiying, 07
}

\author{
Huang, Shuai, 07 \\ Huang, Wenbin, 1R \\ Huang, Xiao, $1 \mathrm{M}$ \\ Huang, Xujie, 10 \\ Hyodo, Masaharu, 01 \\ Jiang, Haibo, OW \\ Jiao, Cheng, OJ \\ Jin, Ning, OR \\ Joo, Jae Young, $\mathrm{OH}$ \\ Kawauchi, Satoko, OS \\ Khokhlov, Demid D., OL \\ Kokubo, Yasuaki, OS \\ Kong, Ming, 05, OQ \\ Korolkov, V. P., $1 \mathrm{E}$ \\ Kozlov, Alexey B., OL \\ Kumar, Manoj, OT \\ Lei, Lihua, 05, 0Q \\ Li, Qiang, IF \\ Li, Xiaotong, OP \\ Li, Xinhang, OY \\ Li, Xuyu, 1Q \\ Li, Yangyang, OX \\ Li, Zhi, 11,15 \\ Liang, Lan, 18 \\ Lin, Guimin, 06 \\ Lin, Tingting, 06 \\ Liv, Baokai, OA \\ Liv, Lin, OX \\ Liu, Yanhua, $1 R$ \\ Liu, Yongji, OA \\ Livshits, Irina L., OU, IP \\ Lu, Qianbo, $1 \mathrm{H}$ \\ LU, Yingming, IF \\ Luo, Yujie, $1 \mathrm{M}$ \\ Luo, Yupeng, IM \\ Machikhin, Alexander S., OL \\ Matoba, Osamu, Ol, OT \\ Miyauchi, Satoru, 0 I \\ MU, Quanquan, IR \\ Nan, Jiang, 17 \\ Nasyrov, R. K., 1E \\ Nishidate, Izumi, OS \\ Nomura, Takanori, OD \\ Pak, Soojong, OF \\ Pan, Sihao, 1s \\ Pan, Zhifeng, is \\ Pape, Christian, OB \\ Park, Hyen Sou, $\mathrm{OH}$ \\ Park, Woojin, OF
}


Peng, Qingaing, OX

Potemin, Igor S., OU, IP

Pozhar, Vitold E., OL

Quan, Xiangyu, OT

Reithmeier, Eduard, OB

Saita, Yusuke, OD

Saito, Shingo, OI

Sato, Manabu, OS

Sato, Shunichi, OS

Schindlbeck, Christopher, OB

Sedukhin, A. G., 1 E

Shen, Weimin, 10

Shen, Yibing, OM

Shi, Zhu, 07

Song, Hai-Zhi, 07

Song, Wen, OJ

Song, Yansong, $O Y$

Stake, Jan, OF

Su, Lijuan, 16

Sun, Xiuhui, OW

Tabachkov, Alexey G., 12

Tao, Zhi-Yong, 17

Vinogradova, Olga A., 12, 13

Voloboy, Alexey, IP

Wang, Chao, 05

Wang, Daodang, 05, 0Q

Wang, Guanjun, OJ

Wang, Kaian, 0J

Wang, Li, 04

Wang, Wanyue, 16

Wang, Xi, OX

Wang, Yan, OU, IP

Wang, Yongtian, OK, IB

Wang, Zhiming M., 07

Wei, Chaoyang, 1Q

Wen, Liyun, 13

Wu, Feng, OE

WU, Quanying, OE

Wu, Shuang, 10

Xie, Lin, OW

Xie, Shuling, 06

Xie, Xiumin, 07

Xie, Zhongming, 05, OQ

$\mathrm{Xu}, \mathrm{Can}, 11,15$

$X \cup$, Haotian, 1B

$X u$, Liwei, $1 F$

$X \cup$, Meng-ting, $1 \mathrm{~A}$

$X \cup$, Qiang, 07

$X U$, Wendong, $1 Q$

$X U$, Yiyun, OY

Yang, Dan, OR

Yang, $\mathrm{He}, \mathrm{O} 6$

Yang, Jiaqiang, $\mathrm{OX}$

Yang, Jidong, OJ

Yang, Kaiyu, OR

Yang, Ruofu, OW

Yang, Tianchi, IR

Yao, Hong, 15

Yin, Shao-yun, OW

Yin, Yamei, OQ
YU, Dingding, $0 G$

Yu, Libo, 07

Zeng, Shao-jun, $1 \mathrm{~A}$

Zeng, Yanhua, 05, OQ

Zhang, Dao, OJ

Zhang, Feng, 11

Zhang, Lei, OY

Zhang, Wentao, 05, OQ

Zhang, Xuewen, 15

Zhang, Yi, OA

Zhang, Yu Ping, OJ

Zhao, Chunyu, 03

Zhao, Jun, 05, OQ

Zhao, Lei, $1 \mathrm{M}$

Zhao, Shiqing, $1 \mathrm{R}$

Zhao, Weirui, OG

Zhao, Zhicheng, 10

Zhdanov, Andrey, OU

Zhdanov, Dmitry D., OU, IP

Zhou, Jiantao, 04

Zhou, Qiang, 07

Zhou, Xiangdong, $1 \mathrm{M}$

Zhu, Jiacheng, 10 


\title{
Symposium Committees
}

\author{
General Chairs \\ Maryellen Giger, President, SPIE and The University of Chicago \\ (United States) \\ Qihuang Gong, President, Chinese Optical Society and Peking \\ University (China)
}

General Co-chairs

Arthur Chiou, National Yang-Ming University (Taiwan, China)

Guangcan Guo, Past President, Chinese Optical Society and University of Science and Technology of China (China)

Zejin Liu, Vice President, Chinese Optical Society and National University of Defense Technology (China)

Technical Program Chairs

Ruxin Li, Vice President, Chinese Optical Society and Shanghai Institute of Optics and Fine Mechanics (China)

Xingde Li, Johns Hopkins University (United States)

Technical Program Co-chairs

Tianchu Li, National Institute of Metrology (China)

Wei Huang, Northwestern Polytechnical University (China)

Ying Gu, Vice President, Chinese Optical Society and PLA General Hospital (China)

Huilin Jiang, Changchun University of Science and Technology (China)

Local Organizing Committee Chair

Xu Liu, Secretary General, Chinese Optical Society and Zhejiang University (China) 
Local Organizing Committee Co-chairs

Wenqing Liu, Vice President, Chinese Optical Society and Anhui Institute of Optics and Fine Mechanics (China)

Guobin Fan, China Academy of Engineering Physics (China)

Local Organizing Committee

Xiaomin Ren, Vice President, Chinese Optical Society and Beijing University of Posts and Telecommunications (China)

Suotang Jia, Vice President, Chinese Optical Society and Shanxi University (China)

Wenjie Wang, Vice President, Chinese Optical Society and Sunny Group Company, Ltd. (China)

Qingming Luo, Huazhong University of Science and Technology (China)

Ping Jia, Changchun Institute of Optics, Fine Mechanics and Physics (China)

Wei Zhao, Xi'an Institute of Optics and Precision Mechanics (China)

Yudong Zhang, Chengdu Branch, Chinese Academy of Sciences (China)

Ninghua Zhu, Institute of Semiconductors (China)

Yongtian Wang, Beijing Institute of Technology (China)

Xiaocong Yuan, Shenzhen University (China)

Limin Tong, Zhejing University (China)

Weimin Chen, Chongqing University (China)

Yidong Huang, Tsinghua University (China)

Tiegen Liu, Tianjin University (China)

Zhiping Zhou, Peking University (China)

Changhe Zhou, Jinan University (China)

Yiping Cui, Southeast University (China)

Zhongwei Fan, Academy of Optoelectronics, CAS (China)

Xiaoying Li, Tianjin University (China)

Yan Li, Deputy Secretary General, Chinese Optical Society and Peking University (China)

Caiwen Ma, Xi' an Institute of Optics and Precision Mechanics (China)

Xinliang Zhang, Huazhong University of Science and Technology (China)

Jianxin Chen, Fujian Normal University (China)

Yihua Hu, College of Electronic Engineering, National Univ. of Defense Technology (China) 
Secretaries-General

Bo Gu, Deputy Secretary General, Chinese Optical Society (China)

Hong Yang, Deputy Secretary General, Chinese Optical Society and

Peking University (China)

Executive Organizing Committee

David J. Bergman, Tel Aviv University (Israel)

Qionghai Dai, Tsinghua University (China)

Keisuke Goda, The University of Tokyo (Japan)

Qihuang Gong, Peking University (China)

Ying Gu, Chinese PLA General Hospital (China)

Guang-Can Guo, University of Science and Technology of China (China)

Byoung S. Ham, Gwangju Institute of Science and Technology

(Korea, Republic of)

Sen Han, University of Shanghai for Science and Technology (China) and Suzhou H\&L Instruments LLC (China)

Werner H. Hofmann, Technische Universität Berlin (Germany)

Minghui Hong, National University of Singapore (Singapore)

Bahram Jalali, University of California, Los Angeles (United States)

Shibin Jiang, AdValue Photonics, Inc. (United States)

Satoshi Kawata, Osaka University (Japan)

Tina E. Kidger, Kidger Optics Associates (United Kingdom)

Baojun Li, Jinan University (China)

Ming Li, Institute of Semiconductors (China)

Ruxin Li, Shanghai Institute of Optics and Fine Mechanics (China)

Xingde Li, Johns Hopkins University (United States)

Jian Liu, PolarOnyx, Inc. (United States)

Tiegen Liu, Tianjin University (China)

Yongfeng Lu, University of Nebraska-Lincoln (United States)

Qingming Luo, Huazhong University of Science and Technology (China)

Yuji Sano, ImPACT (Japan)

Yunlong Sheng, Université Laval (Canada)

Kebin Shi, Peking University (China)

Tsutomu Shimura, The University of Tokyo (Japan)

Upendra N. Singh, NASA Langley Research Center (United States)

Michael G. Somekh, The Hong Kong Polytechnic University

(Hong Kong, China)

Yuguo Tang, Suzhou Institute of Biomedical Engineering and

Technology (China)

Masahiko Tani, University of Fukui (Japan)

Kimio Tatsuno, Koga Research Institute, Ltd. (Japan)

Kevin K. Tsia, The University of Hong Kong (Hong Kong, China)

Kazumi Wada, Massachusetts Institute of Technology (United States) 
Yongtian Wang, Beijing Institute of Technology (China)

Rongshi Xiao, Beijing University of Technology (China)

Hongxing Xu, Wuhan University (China)

Toru Yoshizawa, Tokyo University of Agriculture and Technology (Japan) and 3D Associates (Japan)

Changyuan Yu, The Hong Kong Polytechnic University

(Hong Kong, China)

Chongxiu Yu, Beijing University of Posts and Telecommunications (China)

Xiao-Cong Yuan, Shenzhen University (China)

Xiaoyan Zeng, Huazhong University of Science and Technology (China)

Cunlin Zhang, Capital Normal University (China)

Song Zhang, Purdue University (United States)

Xi-Cheng Zhang, University of Rochester (United States)

Xinliang Zhang, Wuhan National Laboratory for Optoelectronics (China)

Xuping Zhang, Nanjing University (China)

Changhe Zhou, Shanghai Institute of Optics and Fine Mechanics (China)

Zhiping Zhou, Peking University (China)

Dan Zhu, Huazhong University of Science and Technology (China)

Ning Hua Zhu, Institute of Semiconductors (China) 


\title{
Conference Committee
}

\author{
Conference Chairs
}

Yongtian Wang, Beijing Institute of Technology (China)

Tina E. Kidger, Kidger Optics Associates (United Kingdom)

Kimio Tatsuno, Koga Research Institute, Ltd. (Japan)

\section{Conference Program Committee}

Yasuhiro Awatsuji, Kyoto Institute of Technology (Japan)

Jian Bai, Zhejiang University (China)

Pablo Benítez, Universidad Politécnica de Madrid (Spain)

Julie L. Bentley, University of Rochester (United States)

Chunlei Du, Chongqing Institute of Green and Intelligent Technology (China)

Fabian Duerr, Vrije Universiteit Brussel (Belgium)

Yi-Chin Fang, National Kaohsiung First University of Science and Technology (Taiwan, China)

Zexin Feng, Beijing Institute of Technology (China)

Sen Han, University of Shanghai for Science and Technology (China)

Hong Hua, College of Optical Sciences, The University of Arizona (United States)

Jae Young Joo, Korea Photonics Technology Institute

(Korea, Republic of)

Jaisoon Kim, Myongji University (Korea, Republic of)

Michael Kim, Modern High-Tech Company, Ltd. (Korea, Republic of)

Tsuyoshi Konishi, Osaka University (Japan)

Jaejoong Kwon, Samsung Display Company, Ltd.

(Korea, Republic of)

Yun Woo Lee, Korea Research Institute of Standards and Science

(Korea, Republic of)

Irina L. Livshits, ITMO University (Russian Federation)

Osamu Matoba, Kobe University (Japan)

Takanori Nomura, Wakayama University (Japan)

Sung Chan Park, Dankook University (Korea, Republic of)

Gilles Pauliat, Institut d'Optique Graduate School (France)

Xiang Peng, Shenzhen University (China)

Sandy To, The Hong Kong Polytechnic University (Hong Kong, China)

H. Paul Urbach, Technische Universiteit Delft (Netherlands)

Chunyu Zhao, Arizona Optical Metrology LLC (United States)

Jun Zhu, Tsinghua University (China) 


\section{Session Chairs}

1 Joint Keynote Session with Conferences 10814 and 10815

Tina E. Kidger, Kidger Optics Associates (United Kingdom)

Xuping Zhang, Nanjing University (China)

2 Transmission and Interferometric Studies

Tina E. Kidger, Kidger Optics Associates (United Kingdom)

3 Lens Design and Fabrication Methods

Chunyu Zhao, Arizona Optical Metrology LLC (United States)

4 Aspects of Telescopic Optics

Yongtian Wang, Beijing Institute of Technology (China)

5 Illumination Related Issues

Cheng-Hao Ko, National Taiwan University of Science and Technology (Taiwan, China)

$6 \quad$ Stray Light Analysis and Test Techniques

Osamu Matoba, Kobe University (Japan)

7 Imaging Studies and Implementation

Dewen Cheng, Beijing Institute of Technology (China) 